\title{
Effects of number of study environments and learning instructions on free-recall clustering and accuracy
}

\author{
STEVEN M. SMITH \\ Texas A\&M University, College Station, Texas
}

\begin{abstract}
Three word lists were presented to subjects in a single room or in three rooms, and a free-recall test on all three lists was given in a new environmental context. Multiple learning environments improved recall and clustering for subjects given instructions to memorize the words, but improvements did not materialize for those told to construct and remember stories with the words, and for those given incidental learning instructions to rate each word for pleasantness. Results were interpreted to mean that multiple learning environments provide organizational memory cues when learners seek, but still lack ways of organizing, learning material.
\end{abstract}

There is a long history of compelling evidence from laboratory studies that information is more poorly recalled when tested in a new learning environment (e.g., Godden \& Baddeley, 1975; S. Smith \& Guthrie, 1924; S. M. Smith, 1979; S. M. Smith, Glenberg, \& Bjork, 1978). This phenomenon will be referred to as environmentalcontext-dependent forgetting. Learning and testing environments manipulated in such studies have included indoors versus out-of-doors (S. Smith \& Guthrie, 1924); dry land versus underwater (Godden \& Baddeley, 1975); and different-looking laboratory rooms (S. M. Smith et al., 1978).

One procedure found to provide some immunity to context-dependent forgetting involves studying in multiple contexts, rather than in a single environmental setting (S. M. Smith, 1982; S. M. Smith, \& Rothkopf, 1984). This procedure consists simply of dividing the material to be learned into sections and presenting each section to subjects in a different room. As a control, oneroom subjects are also physically disrupted between sessions by having to leave their learning room and return to it for each section to be learned. When subjects are tested in a new environment, both recall and clustering (by input section) increase in the multiple-context condition relative to the one-room condition (S. M. Smith, 1982). The memory improvement due to the multiplelearning-context procedure has not been limited to lists of unrelated words, having been found with educationally realistic materials: S. M. Smith and Rothkopf (1984) gave students an 8-h videotaped minicourse in statistics, and found that students scored better on exams given in

This research was supported by NIMH Grant No. 1 R01 MH39977-01 awarded to the author. Thanks are due to Candy Holley, who helped with collection of the data. Requests for reprints should be sent to Steven M. Smith, Psychology Department, Texas A\&M University, College Station, TX 77842. a new room a week after the course if lectures had occurred in multiple rooms rather than in a single room.

The pattern of findings concerned with multiple learning contexts suggests that multiple contexts provide organizational cues which affect retrieval of the learned material. These organizational cues may direct the memory search undertaken for free recall, thus increasing clustering within segments of learned material. Under certain testing conditions the use of such cues should increase recall as well.

There are situations, however, in which multiple learning contexts have not improved memory relative to oneroom conditions. S. M. Smith (1982), for example, pointed out that recognition was not affected by the number of learning contexts, supporting the notion that the effects are due to retrieval differences rather than to increased learning. S. M. Smith $(1982,1984)$ also found that multiple learning contexts did not improve recall when testing occurred in a reinstated learning context. This was the case whether the learning context was reinstated physically, by returning the subject to the context, or mentally, by asking the subject to think about the previous learning context(s). In fact, some of the evidence suggests that when learning conditions are reinstated, multiple learning contexts may be a slight detriment to recall performance (S. M. Smith, 1984).

As previously noted, increased numbers of learning contexts have been found to raise not only the amount recalled in free recall, but also the amount of within-list clustering (S. M. Smith, 1982; 1984). If environmentalcontext cues are used to guide a memory search, it is reasonable to expect greater within-list clustering for the multiple-context situation because each set of contextual cues is specific to the single list presented in that context. Given a single set of environmental-context cues for all lists, one could neither differentiate among lists nor cluster by lists on the basis of contextual cues. 
The situation described above depends upon the use of contextual cues to guide one's memory search. What of the cases in which contextual cues are not likely to be used to guide a memory search?

If, for example, some better organizational cues were used to store and retrieve information, then contextual cues may have no effect upon recall. Or, if contextual cues are not stored during learning, then they are not likely to be used to guide retrieval, and clustering should remain unaffected by the number of learning contexts used. This line of reasoning suggests that multiple-context cues should exert their greatest effect when the learner seeks, but still lacks, other organizational devices.

One way of manipulating the use of organizational cues which guide storage and retrieval is via learning instructions. In the present experiment some subjects were asked to make up three different stories, one for each list of words. Each story was to incorporate the words on its respective lists. This "story" instruction was designed to induce subjects to organize and retrieve words according to story cues rather than environmental-context cues. Other subjects were given standard "memorize" instructions. It was predicted that the amount of clustering and the number of words recalled would be affected by the number of learning environments in the memory condition, as was the case in previous studies (e.g., Smith, 1982 , 1984), but that clustering and recall would remain unaffected by the number of learning environments in the story condition.

A third group was given identical learning instructions: Subjects rated each word on a pleasantness-rating scale. The purpose of the incidental learning instruction was to prevent the intentional storage of environmental cues which might be used to organize and retrieve list words. It was predicted that the group given the incidental pleasantness-rating instructions (the rating group) would show no effect of number of learning environments on clustering or on number of words recalled.

As in previous studies, all subjects in the present experiment were given a free-recall test in a new environmental context.

\section{METHOD}

\section{Subjects}

The 144 volunteer research participants were students from introductory psychology classes who fulfilled part of a course requirement with their $1 \mathrm{~h}$ of participation. Twenty-four subjects were randomly assigned to each of the six experimental groups.

\section{Procedure}

Subjects studied three word lists spoken by a male voice on an audiocassette recorder. Words were presented at 5-sec intervals. Between lists subjects waited in the hall for $5 \mathrm{~min}$, and were requested to refrain from discussing the experiment or the word lists during the waits. In the oneroom condition, each subject sat in the same seat for all three lists. After the 5-min break following the third list, subjects were taken to a new room (Room D) and were given free-recall instructions, which asked them to write down words from all three lists in any order. They were given $5 \mathrm{~min}$ for the free-recall test. Subjects in the three-room condition went to a new room between list presentations, and changed to a new room again for the final test.
Subjects in the memory group were given instructions to memorize the words on the lists to the best of their ability, and they were warned of a final recall test to occur after presentation of the last list. Those in the story group were instructed to make up a story using the words in each list, and they were told that questions about the different stories would be asked after presentation of the final list. Subjects in the rating group were given 7-point rating scales to be used in rating the subjective pleasantness or unpleasantness of each word independently. A rating of -3 on the scale indicated extreme unpleasantness, +3 indicated extreme pleasantness, and 0 indicated a neutral feeling about a word.

\section{Design}

A 3 (instruction) $\times 2$ (number of rooms) factorial design was used. Instruction for each group was either memory, story, or rating. Number of rooms was either one or three. In the three-room condition, all subjects heard List 1 in Room A, List 2 in Room B, and List 3 in Room C. In the one-room condition one third of the subjects heard all three lists in Room A, one third heard them in Room B, and one third in Room C.

\section{Materials}

Each of the three 32-word lists was made up of common one-syllable, four- and five-letter English nouns drawn randomly from the Kucera and Francis (1967) word-frequency norms. The minimum frequency of any word was 25 per million.

\section{Environmental Contexts}

The four rooms were chosen to be as different from each other overall as possible. Room A was a small $(6 \times 6$-ft) laboratory cubicle with barren walls and a small table folded down from the wall. Room B was a large classroom with a large chalkboard along one wall and windows overlooking the Texas A\&M University campus on two of the other sides. Room $\mathrm{C}$ was a narrow laboratory with bare walls, except for a mirror covering most of one wall, wooden cabinets, and several rows of desk chairs. Room D, the test room used for all subjects, had chalkboards on two opposite ends of the room, windows on a third side, and ventilation fans on the fourth wall. About 20 people could be seated around the four tables, which had been arranged in a rectangle in the center of the room.

\section{RESULTS}

Two separate 2 (number of rooms) $\times 3$ (instruction) ANOVAs were computed, one for number of words recalled, and one for clustering scores.

The ANOVA for total number of words recalled found a significant effect only for instruction $[\mathrm{F}(2,138)=5.76$, $\mathrm{p}<.01, \mathrm{MSe}=88.03$ ]. More words were recalled in the story condition than in either of the other two conditions, and the fewest were recalled in the rating condition (see Table 1). The main effect of number of rooms was not significant $[F(1,138)=.54]$, nor did the number of rooms $\times$ instruction interaction reach significance $[\mathrm{F}(2,138)=1.46, \mathrm{p}=.24]$. Table 1 shows the number of words recalled in each of the experimental conditions.

Table 1

Number of Words Recalled as a Function of Number of Rooms and Learning Instructions

\begin{tabular}{ccc}
\multicolumn{2}{c}{ of Rooms and Learning Instructions } \\
\hline Learning & \multicolumn{2}{c}{ Number of Rooms } \\
\cline { 2 - 3 } Instructions & One & Three \\
\hline Memory & 22.2 & 26.5 \\
Story & 28.2 & 29.3 \\
Rating & 23.5 & 21.2 \\
\hline
\end{tabular}

Note-The maximum possible was 96 words. 
Although the effects were not significant, one-room subjects in the memory condition recalled an average of 22.21 words, as compared with 26.54 words for the three-room memory group. The difference between those two groups (4.33 words) constitutes $19.5 \%$ of the one-room memory group's mean number of words recalled.

Clustering scores (see Table 2) were calculated as the total number of adjacencies in a subject's recalled words divided by the total number of possible adjacencies, given the number of words recalled from each of the three lists. Two words from the same list recalled consecutively were counted as an adjacency. The total number of possible adjacencies was calculated as the total number of words recalled minus the number of lists from which at least one word was recalled.

The ANOVA using clustering scores found a significant effect of instruction $[\mathrm{F}(2,138)=87.45, \mathrm{p}<.001$, MSe $=.025]$. The number of rooms $\times$ instruction interaction was also significant $[\mathrm{F}(2,138)=4.71, \mathrm{p}=.01]$, indicating that clustering for the three-room memory condition (.64) exceeded that of the one-room memory condition (.54), whereas more learning contexts either decreased or did not affect clustering in the story and rating conditions. Clustering was highest for the story group (.84) and lowest for the rating group (.41).

\section{DISCUSSION}

When actively attempting to organize new information in memory, subjects appear to use environmental cues as organizers unless better organizers are available. Those who expected a memory test, the memory and story groups, probably tried to organize the lists of words during learning, preparing themselves for later retrieval. S. M. Smith (1984) suggested that changing learning contexts may alert subjects to use contextual organizational cues during learning. The usefulness of those cues during recall may depend upon a number of factors, such as accessibility of contextual cues at the time of recall, and strength or number of contextual associations (i.e., associations between the learning material and its presentational context). Contextual cues appear to have influenced recall in the memory condition (in which subjects sought, but were not given, efficient organizers), but not in the story condition (in which better organizational cues-the stories themselves-were available).

If subjects do not actively attempt to organize information in memory, then contextual cues are not likely to be actively used as organizers. Such appears to have been the case in the rating condition, where both
Table 2

Clustering as a Function of Number of Rooms and Learning Instructions

\begin{tabular}{lcc}
\hline \multirow{2}{*}{$\begin{array}{c}\text { Learning } \\
\text { Instructions }\end{array}$} & \multicolumn{2}{c}{ Number of Rooms } \\
\cline { 2 - 3 } & One & Three \\
\hline Memory & .54 & .64 \\
Story & .88 & .79 \\
Rating & .42 & .41 \\
\hline
\end{tabular}

Note-The maximum possible clustering was 1.00 .

clustering and recall were uniformly low regardless of number of rooms. The role of intentionality in encoding and retrieval of environmentalcontext information is not known at this time. Yet, whether or not background context is automatically encoded, the results of multiple-learningcontext experiments suggest that background-environment information must be intentionally stored if it is to be used to guide retrieval.

The results of the present experiment further qualify the usefulness of multiple learning contexts, limiting benefits to situations in which learners are actively attempting to organize learning material which is not highly interassociated. Loosely organized knowledge sets could result from a variety of factors, including instructions or learning strategies (shown in the present study), materials (e.g., categorized vs. unrelated), amount or practice, and individual cognitive styles which fail to organize materials.

\section{REFERENCES}

GodDEN, D. R., \& BADDELeY, A. D. (1975) Context-dependent memory in two natural environments: On land and underwater. British Journal of Psychology, 66, 325-331.

KuČERA, H., \& FRANCIS, W. N. (1967). Computational analysis of present-day American English. Providence, RI: Brown University Press.

SMIth, S., \& GUTHRIE, E. R. (1924). General psychology in terms of behavior. New York: Appleton-Century.

SмIтH, S. M. (1979). Remembering in and out of context. Journal of Experimental Psychology: Human Learning \& Memory, 5, 460-471.

SмIтH, S. M. (1982). Enhancement of recall using multiple environmental contexts during learning. Memory \& Cognition, 10, 405-412.

SMITH, S. M. (1984). A comparison of two techniques for reducing context-dependent forgetting. Memory \& Cognition, 12, 477-482.

Smith, S. M., GlenberG, A. M., \& BJorK, R. A. (1978). Environmental context and human memory. Memory \& Cognition, 6, 342-353.

SMITH, S. M., \& RoTHKOPF, E. Z. (1984). Contextual enrichment and distribution of practice in the classroom. Cognition \& Instruction, 1, 341-358.

(Manuscript received for publication July 9, 1985.) 